\title{
Tractarian Objects and Logical Categories
}

\author{
Colin Johnston
}

\begin{abstract}
It has been much debated whether the Tractarian objects are what Russell would have called particulars or whether they include also properties and relations. This paper claims that the debate is misguided: there is no logical category such that Wittgenstein intended the reader of the Tractatus to understand his objects either as providing examples of or as not providing examples of that category. This is not to say that Wittgenstein set himself against the very idea of a logical category: quite the contrary. However, where Russell presents his logical variety of particulars and the various types of universal, and Frege presents his of objects and the various types of function, Wittgenstein denies the propriety of such a priori expositions. Wittgenstein envisages a variety of logical types of entity but insists that the nature of these types is something to be discovered only through analysis.
\end{abstract}

This paper begins with a review of a familiar debate whether Tractarian objects are particulars or include also universals. In the second section I abstract from that debate: a proposal is made rather for framing the question of how Tractarian objects are to be placed with the logical ontologies of Frege and Russell. Section three notes some equivalences for that question, so framed, and takes a first look at Wittgenstein's response. Wittgenstein's position is then explored more fully in section four. The penultimate section five draws together the conclusions of sections two through four and compares them with the debate discussed in section one and also with the positions of certain exegetes not party to that debate. Section six deals with some loose ends and makes a quick connection to Wittgenstein's later philosophy.

\section{1.}

Hide Ishiguro advises us to keep in mind in reading the Tractatus that Wittgenstein's expression 'object' ('Gegenstand') is "used in the very special way Frege defined" (Ishiguro (2001, 28)). Given Wittgenstein's knowledge of and great respect for Frege's works, this suggestion certainly demands attention. It does however face an obvious, prima facie difficulty stemming from the fact that the Tractatus does not offer classes of entity of reference contrasting with the Tractarian objects. Where Fregean objects constitute only one of a variety of logical types of entity of reference, the other types being constituted by Fregean functions of differing kinds, the Tractatus introduces the word 'object' as synonymous with 'entity' and 'thing' (Tractatus 2.01). What may be referred to the Tractatus calls an object. Given, then, that Tractarian objects do not occupy a place in a Tractarian variety of entities of reference comparable to the place occupied by Fregean objects in the Fregean variety of entities of reference, how is the suggestion to be made sense of that Tractarian and Fregean objects are of a piece?

To respond here, one would need to see how Frege pins down his idea of an object other than in its opposition within the field of entities of reference to his idea of a function. The obvious line to investigate is Frege's doctrine that objects are what are referred to by Fregean proper names.

Alongside Frege's ontological system of categories of entity sits a logical system of categories of linguistic expression. And these two systems are connected by reference: what a proper name refers to is an object; what a function expression of a certain kind refers to is a function of the corresponding kind. With this body of doctrine in view, the prospect of assimilating Fregean and Tractarian objects beckons in the following way. First, one will propose that Wittgenstein is working with a system of expression types comparable to that of Frege. Next one will suggest that Tractarian objects are linked in reference to a Tractarian expression type comparable to Frege's proper name. And finally one will claim that Tractarian expressions of types other than that comparable to Frege's proper name do not refer. It is not, one will find the Tractatus to assert, the business of concept expressions to refer: there are no such things as concepts. Reference is the business only of proper names.

Passages can be found in the Tractatus and elsewhere to support a proposal of this kind. First one will read Tractatus 3.203 and 3.221 ("A name refers to an object" and "Objects can ... be named") 
as indicating that Tractarian names constitute the Tractarian expression type to be compared to the Fregean proper name. Subsequently one may turn to Tractatus 3.1432:

Instead of, 'The complex sign " $a \mathrm{R} b$ " says that $a$ stands to $b$ in the relation R', we ought to put, 'That " $a$ " stands to " $b$ " in a certain relation says that $a \mathrm{R} b$.' (Wittgenstein (1961, $3.1432))$

To assert that the complex sign ' $a \mathrm{R} b$ ' says that $a$ stands to $b$ in the relation $\mathrm{R}$ is, Wittgenstein claims, misleading. Rather we should say: that ' $a$ ' stands to ' $b$ ' in a certain relation says that $a \mathrm{R} b$. A difference Wittgenstein is concerned to have us note between these two readings, one might then propose, is the intimation by the former but not the latter that there is a relation $\mathrm{R}$ to which the expression ' $\mathrm{R}$ ' in ' $\mathrm{aRb}$ ' refers.

Tractatus 3.1432 is drawn directly from the 1913 Notes on Logic ${ }^{1}$ in which Wittgenstein also wrote:

In "aRb" " $R$ " looks like a substantive but it is not one. What symbolises in "aRb" is that " $R$ " occurs between " $a$ " and " $b$ ". Hence " $R$ " is not the indefinable in "aRb". Similarly in " $\varphi x ", " \varphi "$ looks like a substantive but is not one. (Wittgenstein $(1979,98)$ )

Rather:

What symbolises in $\varphi \xi$ is that $\varphi$ stands to the left of a proper name. (Wittgenstein (1979, 116)

The idea of these passages, as one might find it, would be first that Frege has slightly misidentified concept expressions and second that he has mistaken their semantic role. Where Frege would say that the symbolising elements of ' $a R b$ ' are ' $a$ ', ' $b$ ' and ' ( )R( )' and that the last of these refers to a concept, Wittgenstein claims that the symbolising elements are ' $\mathrm{a}$ ', ' $\mathrm{b}$ ' and that ' $\mathrm{R}$ ' occurs between two names, and further that the last of these does not refer at all but has the role instead of effecting an assertion of a certain kind.

Given that Wittgenstein's most immediate interlocutor in 1913 is not Frege but Russell, one may prefer to frame the proposal in current view in Russellian terms. Tractarian objects, one will suggest, are Russellian particulars; there are no such things as Russellian universals. Adopting this position, Thomas Ricketts has for instance written:

Russell takes relations to be a type of thing - they are constituents of facts, objects of acquaintance, and the designata of names ... . All this is what the reality of relations comes to for him. So conceived, Wittgenstein rejects the reality of relations, Russell's most cherished ontological thesis. Relations are not things, are not entities; relations cannot be labelled or designated. Unlike "a" and "b," "R" is not a symbol in "aRb." Instead, roughly put, the holding of a relation over objects is symbolized by the holding of a relation over names of those objects. (Ricketts $(1996,72)$ )

Nicholas Griffin agrees:

In the Tractatus Wittgenstein speaks of elementary propositions as combinations of names, and states of affairs as combinations of objects, with no special explanation of what he means by 'names' or 'objects'. But unless there was a radical change in the way he himself used these words [between writing the Notes on Logic and writing the Tractatus], then by 'objects' he must have meant particulars and so by 'names' names of particulars. (Griffin $(1964,53))$

Griffin proceeds explicitly to assert that Tractarian "[o]bjects are particulars" (Griffin $(1964,61))$. Such exegetical claims have, however, been hotly disputed:

Wittgenstein counts as 'things' not only individual objects but also predicates with different numbers of places. (Stenius $(1960,63)$ )

[T] he objects of the Tractatus included relations. (Hacker $(1989,70)$ ) 
There is virtually conclusive evidence that in the Tractatus Wittgenstein included properties, relations, and functions (in logicians' usual sense, meaning certain kinds of relations) among his 'objects'. (Hintikka and Hintikka (1986, 32-33))

What, then, is this "virtually conclusive evidence"?

A first thing that might be adduced in favour of the position that Tractarian objects include properties and relations is an apparent tension between the position of Griffin and Ricketts and the assertion of Tractatus 2.01 that a state of affairs is a combination of objects (plural). An elementary proposition 'asserts the existence of a state of affairs' (Tractatus 4.21). If ' $\varphi$ ' in a subject-predicate proposition ' $\varphi a$ ' is not a name, then it would seem that the state of affairs whose existence the proposition asserts could involve only one object, $a$. Further support for the suggestion that objects include relations may then be gathered from certain passages in non-Tractarian texts. In June 1915 Wittgenstein wrote:

Relations and properties, etc. are objects too. (Wittgenstein $(1979,61)$ )

And Wittgenstein was recorded in 1930 or 1931 by Desmond Lee as offering the following explanation of Tractatus 2.01:

2.01. "An atomic fact is a combination of objects (entities, things)". Objects etc. is here used for such things as a colour, a point in visual space etc. ... "Objects" also include relations: a proposition is not two things connected by a relation. "Thing" and "relation" are on the same level. (Wittgenstein $(1980,120)$ )

Running then with the idea that Tractarian objects do indeed include relations, one will look to offer an understanding of the functioning of the proposition ' $\mathrm{aRb}$ ' consonant, or at least consistent, with Tractatus 3.1432. A suggestion one might make here is that Wittgenstein's idea, as it develops into the Tractatus, becomes that there are three names in the proposition ' $\mathrm{aRb}$ ', but that these are not ' $a$ ', 'R' and ' $b$ ': rather they are ' $a$ ', ' $b$ ' and the relation of being on either side of the letter ' $R$ '. As ' $a$ ' and ' $b$ ' name the objects $a$ and $b$, so the relation of being on either side of the letter ' $R$ ' names a certain relation. Thus Stenius has written:

[T]here are two kinds of names:

(a) names of individual objects, which themselves belong to the category of individual objects,

(b) names of predicates, which themselves belong to the category of predicates and must have as many places as their denominate.

According to this definition the names appearing in [the sentence ' $\mathrm{mSe}$ '] are ' $\mathrm{m}$ ', ' $\mathrm{e}$ ' and the ' $\mathrm{S}$ '-relation [that is, the relation which holds between two objects when the first is to the left and the second to the right of the letter 'S']. (Stenius $(1960,136)$ )

And Hintikka and Hintikka write:

Here what a name is, for Wittgenstein, is not a linguistic symbol (e.g., the letter ' $\mathrm{R}$ '), but a linguistic relation (i.e. that of flanking a particular letter). (Hintikka and Hintikka (1986, 38))

Part of the difficulty of accepting the interpretation offered here is terminological. A name certainly seems to be always a word, not a linguistic property or linguistic relation. Furthermore, Frege sets up a contrast between saturated entities, which he calls objects, and unsaturated entities, which he terms functions. On the interpretation presented here, Wittgenstein departs sharply from Frege's terminology in this respect, for according to this interpretation Wittgenstein in the Tractatus calls both kinds of entities objects. (Hintikka and Hintikka $(1986,39))$

It can thus be agreed by both sides in this debate over the objecthood of relations/functions that the proposition ' $a R b$ ' consists in the fact that an ' $R$ ' is flanked to the left by an ' $a$ ' and to the right by a ' $b$ '. Where the two sides will disagree, however, is on what names are involved in this fact. For Griffin and Ricketts the proposition's two names are ' $a$ ' and ' $b$ ', and that these two names are combined in a certain way, namely that they stand on the left and right hand side respectively of an ' $R$ ', 
is what says that aRb. For Stenius and Hintikka and Hintikka the names of the proposition 'aRb' are ' $a$ ', ' $b$ ', and the relation of standing to the left and right of an 'R', and what says that aRb is that these three names are combined together in a certain way - in that way, that is, in which a relation and two particulars are combined when the relation holds in a certain direction between the two particulars.

Such, then, are the terms of a debate regarding the logical categorical status of Tractarian objects. I shall not explore this disagreement any further. Nor do I want to offer an adjudication between the two sides: it will be a conclusion of this paper that the debate is misguided. Rather, let's return afresh to the question of how to place Tractarian objects with the Fregean and Russellian logical varieties. But instead of jumping in as we did before with a positive proposal, let's begin instead by enquiring after the idea Frege and Russell present of a logical variety.

\section{2.}

Russell's logical categories of particular, predicate and relation take their primary rise from his theory of atomic complexes. In brief, this theory runs as follows. A complex has constituents. These compose the complex and are said variously to figure, occur, appear or enter in the complex. Furtherand here is the theory's core - entities figure (occur etc.) in complexes different ways. An entity, Russell holds, may appear in a complex either as a term or as a relating relation, and these appearances follow the pattern that in any (atomic) complex one entity appears as a relating relation and all the others as terms. From this, Russell then derives his notions of a term and an $n$-ary relation. A term is an entity which may appear in a complex as a term; an n-ary relation is an entity which may appear as a relating relation in a complex in which $\mathrm{n}$ entities appear as terms. A unary relation we call a predicate; relations of all orders we call universals; terms which are not universals we call particulars. So in 1913 Russell wrote:

In any complex, there are at least two kinds of constituents, namely the terms related, and the relation which unites them. ... In (say) "A precedes B", A and B occur differently from the way in which "precedes" occurs. ... An entity which can occur in a complex as "precedes" occurs in "A precedes B" will be called a relation. When it does occur in this way in a complex, it will be called a "relating relation" in that complex....

Atomic complexes may be classified according to the number of terms other than the relating relation that they contain; we will call them dual complexes if they contain two terms, and so on. Relations may be similarly classified: relations which can be relating in dual complexes will be called dual relations, and so on.

$\ldots$

It may be that there are complexes in which there is only one term and one predicate, where the predicate occurs as relations occur in other complexes. In that case, predicates will be defined as entities occurring in this manner in complexes containing only one other entity....

Relations and predicates together will be called "universals". (Russell (1984, 80-81))

A particular is defined as an entity which can only enter into complexes as the subject of a predicate or as one of the terms of a relation, never as itself a predicate or a relation. (Russell $(1984,55-56)$ )

Frege's logical categories are also characterised essentially by their combinatorial powers. The notion of combination in play with Frege is rather different from that in play with Russell: in place of entities combining as parts to make complex wholes, Frege's theory at the level of reference is of entities combining as function and argument to deliver a value. Very roughly, the theory is that a Fregean object is a possible argument of a Fregean first order function, and a Fregean function of order $\mathrm{n}$ is a possible argument of a Fregean function of order $\mathrm{n}+1$. [CHANGE THIS: NOT 'POSSIBLE ARGUMENT' BUT SIMPLY 'ARGUMENT'] More, Fregean functions may have multiple argument places, and this introduces distinct logical categories: a second order function may not take in the same argument place both a first order function of one argument and a first order function of two arguments. A function may also have argument places of different levels and this likewise makes for distinct categories. 
The details of the Fregean and Russellian systems are not our current concern. Nor shall I explore or compare the divergent ideas of combination employed by Russell and Frege. The point to note here is rather that Frege and Russell are both involved in systems of entity combination, and that the logical categories of entity which they advance are characterised essentially by their roles in the combinatorial system. Characterising each Fregean or Russellian logical category is a unique set of combinatorial powers, each such power being specified in terms of the logical categories only.

Now we noted above that there are in the Tractatus no classes of entity contrasting to the objects. It might therefore seem that Wittgenstein does not have the resources to provide a combinatorial system on the Fregean or Russellian model. To think this, though, is to think of Tractarian objects as constituting a single logical kind. We have seen one way of doing this, namely by tying the notion of an object to a single expression kind. But we have also seen that such a tie need not be made and that if it is not, space is available for divisions of logical type amongst the objects. (We have seen the suggestion made, for instance, that Tractarian objects divide into particulars, properties and relations.) As Wittgenstein uses them, one might propose, 'object' is a catch-all word meaning 'entity of reference', and 'name' a catch-all word meaning 'referring expression'. The possibility will then be open of dividing up the objects into logical categories characterised by their combinatorial powers.

Wittgenstein introduces his notion of an object as follows:

A state of affairs is a combination of objects (entities, things). (Wittgenstein $(1961,2.01)$ )

He continues:

It is essential to things that they should be possible constituents of states of affairs. In logic nothing is accidental: if a thing can occur in a state of affairs, the possibility of the state of affairs must be written into the thing itself. (Wittgenstein (1961, 2.011-2.012))

The possibility of its occurring in states of affairs is the form of an object. (Wittgenstein $(1961,2.0141))$

If two objects have the same logical form, the only distinction between them, apart from their external properties, is that they are different. (Wittgenstein $(1961,2.0233)$ )

Objects combine to form states of affairs. The possibilities an object has for such combination are internal to it and constitute its logical form.

A Tractarian object has an internal, logical nature which is its powers to combine with other objects to form states of affairs. This would seem to place Wittgenstein firmly in the company of Frege and Russell and their combinatorial varieties. As Frege and Russell present a variety of logical categories of entity of reference, each category characterised by its combinatorial powers (whether that be function-argument or part-whole combination), so Wittgenstein envisages a variety of logical forms of entity of reference, these forms being a matter of combinabilities to form states of affairs. Accepting this comparison, however, something that stands out in the above sections from the Tractatus is that Wittgenstein does there no more than envisage a logical variety. Wittgenstein's presentation at this point is made in the abstract: he does not specify what the various forms of object might be. For Frege, Fregean objects and the variety of types of Fregean function constitute the available forms of entity; for Russell the forms of entity are particulars, properties and relations of the various orders. But what forms does the Tractarian Wittgenstein imagine there to be?

3.

Let's recall the link made by Frege between his variety of entities of reference and his variety of referring expressions. What a Fregean proper name refers to is an object; what a Fregean function expression of a certain kind refers to is a function of that same kind. It will be useful for us at this point to note that Wittgenstein is involved in a similar linking.

An elementary proposition, Wittgenstein asserts, consists of names; it is a combination of names (Tractatus 4.0311, 4.22). And as objects are combinatorially discriminating, so too are the names. Names may combine with each other in certain ways but not in others to form elementary propositions. It is then a central plank of Wittgenstein's philosophy of language that there is a match between these two systems of combinability, that of the objects and that of the names. The 
combinatorial forms found within them are the same. Further, an object of a certain form may be referred to only by a name of that same form. What a name of a certain logical type refers to is an object of that same logical type.

This Tractarian theory is not brought up here to be explained or elucidated: the point is only to provide for a recasting of the question of what forms of Tractarian objects there are. It is to allow for us to see that that question is equivalent, given certain central features of Wittgenstein's philosophy of language, to the question of what forms of Tractarian names (that is, referring expressions) there are. And the answer to this latter question of what combinatorial types of names there are, we can further note, will be given by saying what types of combinations of names are possible. That is, we will be told what forms of object Wittgenstein imagines there to be just in case we are told what his elementary propositional types (forms) are.

So what forms of elementary proposition does Wittgenstein take there to be? Here one might hope to make recourse to a Wittgensteinian concept script. The idea of a concept script is employed in various ways by Frege, Russell and Wittgenstein. In one of the idea's outlines, a concept script is a language whose surface syntax is logical syntax: it is a language whose propositions are such that we may identify their surface syntactic elements with their logical elements. To see what propositional forms Frege, Russell and Wittgenstein hold there to be we thus need only look at the (surface) syntax of their concept scripts. With Frege and Russell this tactic is immediately rewarding: on looking at Russell's concept script, for example, we find there encoded his subject-predicate, dual relational, triple relational etc. forms. With Wittgenstein, by contrast, we struggle. Whilst we find on thumbing through the Tractatus an endorsement of the general idea of a concept script (Tractatus 3.325), we nowhere come across any particular such construction. Wittgenstein, it might disappointingly seem, is keeping his elementary propositional form cards tight up to his chest.

The suspicion that Wittgenstein is being cagey on this matter is not however borne out by the text. On the contrary, Wittgenstein directly poses himself the challenge:

We now have to answer a priori the question about all the possible forms of elementary propositions. (Wittgenstein $(1961,5.55)$ )

This challenge is not subsequently ducked by Wittgenstein: rather he rejects it as misplaced:

The application of logic decides what elementary propositions there are.

What belongs to its application, logic cannot anticipate.

It is clear that logic must not clash with its application.

Therefore logic and its application must not overlap.

If I cannot say a priori what elementary propositions there are, then the attempt to do so must lead to obvious nonsense. (Wittgenstein (1961, 5.557-5.5571))

There is no saying a priori what forms of elementary propositions there are, and so no saying a priori what types (forms) of names, and so again of objects there are. A demand for an exposition of the logical categories of entity, insofar as that is a request for something to be given a priori, is misguided.

But what notion of 'a priori' is Wittgenstein making use of here? In play is an opposition between logic and its application: the application of logic decides what elementary propositions there are; logic cannot anticipate what belongs to its application, and so it cannot anticipate the elementary forms. But what is meant by logic in this context? And what by its application?

\section{4.}

It is a distinctive claim of the Tractatus that relations of logical entailment amongst propositions result from their truth functional structuring only. More, Wittgenstein is concerned in his book to provide a general characterisation of such structuring and thus of logical entailment. Indeed, the provision of just such a characterisation - the provision, that is, of the general form of the proposition - is a significant climax of the Tractatus.

A second and connected Tractarian doctrine is that of the possibility of analysis. There is, Wittgenstein holds, a procedure applying to propositions of natural language whose achievement is the uncovering of truth functional structure. A proposition of English or German may be analysed and the result of such an analysis will be a display of how that proposition is composed, truth functionally, out of other, truth functionally simpler propositions. More, there is the possibility of a complete analysis in 
which it is uncovered how the analysed proposition is composed out of truth functionally simple propositions - out, that is, of elementary propositions which consist of names only.

Approaching Tractatus 5.557-5.5571 in the context of these aspects of Wittgenstein's thought, a suggestion one might make is that logic, as Wittgenstein uses the word in 5.557, means truth functionality. And by the application of logic, the suggestion will continue, Wittgenstein means here the performance of truth functional analysis. To apply logic is to uncover what truth functional structure is had by a proposition. The proposal will thus be that Wittgenstein's use of 'a priori' in these contexts means 'in advance of the performance of analysis', and the assertion that the application of logic decides what forms of elementary propositions there are will be the assertion that the elementary forms become discernable only through analysis. Whilst the notion of truth functionality is given $a$ priori, the elementary forms will in this sense be available only a posteriori. In Some Remarks on Logical Form ${ }^{2}$ Wittgenstein writes:

If we try to analyze any given propositions we shall find in general that they are logical sums, products or other truth functions of simpler propositions. But our analysis, if carried far enough, must come to the point where it reaches propositional forms which are not themselves composed of simpler propositional forms. We must eventually reach the ultimate connection of the terms, the immediate connection which cannot be broken without destroying the propositional form as such. The propositions which represent this ultimate connexion of terms I call, after B. Russell, atomic propositions. ... It is the task of the theory of knowledge to find them and to understand their construction out of the words or symbols. This task is very difficult, and Philosophy has hardly yet begun to tackle it at some points. (Wittgenstein $(1993,29)$ )

If we analyse propositions we find that they are truth functions of simpler propositions. Pursuing this far enough, we will eventually arrive at truth-functionally simple elementary propositions. To do this, to find the elementary propositions and understand their construction is the task of Philosophy. 'The idea' here, Wittgenstein continues:

is to express in an appropriate symbolism what in ordinary language leads to endless misunderstandings. That is to say, where ordinary language disguises logical structure, where it allows the formation of pseudopropositions, where it uses one term in an infinity of different meanings, we must replace it by a symbolism which gives a clear picture of the logical structure, excludes pseudopropositions, and uses its terms unambiguously. (Wittgenstein $(1993,29-30)$ )

Our ambition in analysis is to rewrite propositions of ordinary language in a symbolism which gives a clear picture of their logical structure: a clear picture, that is, of which truth functions they are of which elementary propositions.

If we were to focus on this idea of rewriting in a concept script and lose sight of Wittgenstein's earlier assertion that it is a task of analysis to find the elementary propositions and understand their construction, one might suppose that the development of a concept script would be a precursor to analysis. Analysis, one might suppose, consists in translating propositions of ordinary language into a previously developed concept symbolism. Heading off this misunderstanding, Wittgenstein continues:

Now we can only substitute a clear symbolism for the unprecise one by inspecting the phenomena which we want to describe, thus trying to understand their logical multiplicity. (Wittgenstein $(1993,30)$ )

And in a 1929 discussion with Waismann entitled 'Objects' Wittgenstein says:

Only when we analyse phenomena logically shall we know what form elementary propositions have. (Wittgenstein (1979a, 42))

It is, Wittgenstein held, only through the performance of analysis that we may develop a clear symbolism, substituting it for the unprecise one of everyday. A concept script will encode the elementary propositional forms and uncovering what these are is a principal ambition of the project of analysis. 
Wittgenstein is fundamentally opposed to the idea that one first constructs a concept script and only subsequently turns one's attention to particular propositions of everyday, attempting to see how they might be written in the constructed symbolism. One does not first work out what propositional forms there are and then subsequently decide which of these forms is had by some English sentence. Those are not the two steps of giving logic and applying it. The two steps of giving logic and applying it are rather first to characterise truth functionality, and subsequently to uncover truth functional structuring within propositions. And it is only through the second of these that the elementary forms will become apparent, that a concept-script will become available.

Wittgenstein finishes his line of thought in Some Remarks on Logical Form as follows:

One is often tempted to ask from an a priori standpoint: What, after all, can be the only forms of atomic propositions, and to answer, e.g., subject-predicate and the relational propositions with two or more terms further, perhaps, propositions relating predicates and relations to one another, and so on. But this, I believe, is mere playing with words. An atomic form cannot be foreseen. And it would be surprising if the actual phenomena had nothing more to teach us about their structure. To such conjectures about the structure of atomic propositions, we are led by our ordinary language, which uses the subject-predicate and the relational form. But in this our language is misleading. (Wittgenstein $(1993,30)$ )

The same point is made in the discussion with Waismann:

Now I think that there is one principle governing the whole domain of elementary propositions, and this principle states that one cannot foresee the form of elementary propositions. It is just ridiculous to think that we could make do with the ordinary structure of our everyday language, with subject-predicate, with dual relations, and so forth. (Wittgenstein $(1979 \mathrm{a}, 42)$ )

At Tractatus 5.5571 Wittgenstein declares the attempt to say a priori what the elementary forms are (what the elementary forms must be) certain to lead to nonsense; in Some Remarks on Logical Form he calls it "mere playing with words". We may be led by the use in our ordinary language of certain surface grammatical forms (e.g. the English or German subject-predicate form) into thinking that we can lay down the possible logical forms of propositions in advance of analysis, but it would be a mistake so to think - "in this our language is misleading". For Wittgenstein, Frege and Russell were misled in just this way when they constructed their concept scripts.

5.

As Frege and Russell, the Tractarian Wittgenstein envisages a variety of logical types of entity of reference. However, where Frege and Russell lay out their logical varieties in a certain sense a priori, Wittgenstein thinks that such expositions are mistaken. What forms of elementary proposition there are, Wittgenstein insists, will become available to us only through the pursuit of analysis. What forms of name and so what forms of entity there are will in this sense be apparent only a posteriori. Of course, the Tractatus does not itself engage in analysis - this is something for philosophers to do after the book has been read. The Tractarian Wittgenstein is thus self-consciously agnostic with regard to the logical types of entity.

It is worth repeating the passage we have taken to this conclusion. In section two I characterised the Fregean and Russellian notions of an entity's logical type as pertaining essentially to basic combinatorial powers. Wittgenstein, I then suggested, also operates with such a notion: entities have 'logical forms' characterised by their powers to combine to form states of affairs. Frege and Russell do not, however, merely present an idea of a combinatorial type: they add flesh to the skeleton and lay down what they consider the combinatorial types (forms) actually to be. Frege offers his combinatorial variety of Fregean objects and the various kinds of Fregean function, and Russell his of particulars and the various kinds of universal. What flesh, we were left asking at the end of section two, does Wittgenstein give to his bones: what logical forms of entity does Wittgenstein imagine there to be? Section three then took this question forward, recasting it first as the question what logical forms of name Wittgenstein imagines there to be, and subsequently as the question what logical forms of elementary proposition Wittgenstein imagines there to be. Elementary propositions are combinations of names, and names share a combinatorial form with the objects to which they refer. We will thus be told what forms of object Wittgenstein imagines there to be just in case we have been 
told what types of name-combinations (that is, elementary propositions) he envisages. At end of section three, however, we noted Wittgenstein's declaration that the question of the elementary propositional forms (and hence of the forms of objects) cannot be answered 'a priori'. The subsequent task of section four was to explain what Wittgenstein intended in this context by 'a priori'. 'A priori' means here, I argued, 'in advance of the performance of analysis'. It is only through the performance of analysis that the elementary forms will become available. It is only through the performance of analysis that we can find out what the logical types of entity are.

Looking back at the debate discussed above in section one of this paper, we will find it misconceived. To argue whether Wittgenstein intended us to take Tractarian objects to be particulars, or to include relations, is a mistake. The Tractarian Wittgenstein does not think that any such would-be logical category terms as 'particular' or 'relation' have a priori application. A suggestion made in advance of the pursuit of truth-functional analysis that Tractarian objects include, or do not include, relations is something Wittgenstein would have seen as "mere playing with words".

That the debate reviewed section one is mistaken is not a novel proposal. Anthony Kenny has for instance written:

Students of the Tractatus disagree whether that work is to be taken in a nominalist or Platonist sense: whether, that is to say, the objects which form the fixed substance of the world are to be interpreted as individuals or as universals. The Notebooks that precede the Tractatus show that Wittgenstein himself veered between the nominalist and Platonist positions, and provide to that extent support for the rival interpretations of the Tractatus. However, it seems to me no accident that it is difficult to decide the question from the study of the Tractatus alone; when writing the book Wittgenstein chose his words carefully so as not to adopt either of the positions about which the Notebooks express his doubts and hesitations. (Kenny $(1984,16)$ )

David Pears agrees:

It is possible that the Tractatus does not contain a definite answer to the question, whether all objects are particulars. (Pears $(1987,137))$

There are important sources of evidence not only in his preparatory work for the book, but also in his later comments on it, many of which imply that he had at least allowed for the possibility of counting relations and properties as objects. But in the book itself he seems to be more non-committal than in his preparatory work for it, and, therefore, almost certainly deliberately non-committal. (Pears $(1987,139)$ )

Pears and Kenny correctly maintain that Wittgenstein offered no answer to the question of nominalism versus Platonism. Their suggestion seems to be, however, that Wittgenstein withheld judgment on the matter, that whilst Wittgenstein found nothing wrong with the question it was nonetheless not his concern in the Tractatus to adjudicate which of the two answers is correct. This exegetical position, whilst rejecting the propriety of debating whether the Tractarian Wittgenstein was a nominalist, remains quite different from mine. The Tractarian Wittgenstein does not merely avoid giving an answer to the question whether objects include universals: he rejects the terms of the question. Thus he says in the discussion with Waismann:

When Frege and Russell spoke of objects they always had in mind things that are, in language, represented by nouns. ... [Their] whole conception of objects is hence very closely connected with the subject-predicate form of propositions. It is clear that where there is no subject-predicate form it is also impossible to speak of objects in this sense. (Wittgenstein $(1979 \mathrm{a}, 41)$ )

Our ignorance of the structure of elementary propositions means that we can make nothing of a wouldbe logical category term such as Frege's term 'object'. "Here", as Wittgenstein sees it, "is an area where there is no hypothesis" (Wittgenstein (1979a, 42)).

The philosopher I would like rather to enlist in support of the claims of this paper is Frank Ramsey. Ramsey, we can quickly note, occupies a privileged exegetical position. In September 1923 he paid a visit to Wittgenstein in Puchberg where, over the course of a fortnight, Wittgenstein spent five hours a day going through the Tractatus with him line by line. ${ }^{3}$ It was important to Wittgenstein that someone understand him, and Ramsey - the outstanding logician-philosopher of the 1920s - was best equipped for that purpose. More visits were subsequently made to Austria and a philosophical 
correspondence was maintained. Turning to what Ramsey had to say, the key piece with regard to our current concern is the 1925 paper Universals whose stated purpose is "to consider whether there is a fundamental division of objects into two classes, particulars and universals" (Ramsey $(1990,8)$ ). According to Russell, Ramsey writes, "terms are divided into individuals or particulars, qualities and relations, qualities and relations being grouped together as universals" (Ramsey (1990, 9)). Appealing at several points to the ideas of Wittgenstein, Ramsey argues at length against this position, concluding that an unbiased logician will not be concerned to make any distinction between different types of things.

In response to this rejection of his theory, Ramsey then imagines Russell as countering that:

all atomic propositions are of the forms $\mathrm{R}_{1}(\mathrm{x}), \mathrm{R}_{2}(\mathrm{x}, \mathrm{y}), \mathrm{R}_{3}(\mathrm{x}, \mathrm{y}, \mathrm{z})$, etc., and so [the logician] can define individuals as terms which can occur in propositions with any number of terms; whereas of course an $n$-termed relation could only occur in a proposition with $n+1$ terms. (Ramsey $(1990,29))$

To this Ramsey replies:

But this assumes [Russell's] theory as to the constitution of atomic facts, that each must contain a term of a special kind, called a universal; a theory we found to be utterly groundless. The truth is that we know and can know nothing whatever about the forms of atomic propositions; we do not know whether some or all objects can occur in more than one form of atomic proposition; and there is obviously no way of deciding any such question. We cannot even tell that there are not atomic facts consisting of two terms of the same type. (Ramsey 1990, 29))

The failure to recognise this, Ramsey finally suggests, is the root cause of the "great muddle" which is the theory of universals:

Of all philosophers Wittgenstein alone has seen through this muddle and declared that about the forms of atomic propositions we can know nothing whatever. (Ramsey $(1990,30)$ )

This is, I think, an overstatement of the case. Wittgenstein asserts that we can know nothing a priori about the forms of atomic propositions, that the unbiased logician will not be concerned to make any $a$ priori distinction between different types of things. This leaves open the possibility of a posteriori knowledge of atomic forms. Indeed, Wittgenstein's Tractarian claim that what elementary propositions there are is decided by the application of logic (Tractatus 5.557), and his 1929 claim that "[o]nly when we analyse phenomena logically shall we know what form elementary propositions have"

(Wittgenstein (1979a, 42)), would appear to endorse this possibility as genuine. Ramsey's strong claim here may nonetheless not be indefensible. Whilst Wittgenstein holds every proposition to have a completed truth-functional analysis, the innumerability of logical forms (Tractatus 4.128) may be thought to entail the impossibility of human knowledge of such analyses. One might ascribe to Wittgenstein the position that we will be able to construct improved symbolisms, gaining partial knowledge of logical forms, but will be unable to reach a symbolism offering full knowledge of logical forms. I shall not here argue the point too vigorously: Ramsey is an ally in ascribing to Wittgenstein the thought that the historical theories of universals and particulars are 'muddles' predicated upon the false presumption that we have knowledge of atomic forms. More, in a subsequent note to his paper Ramsey adjusts his position to my preferred interpretation:

When I wrote my article I was sure that it was impossible to discover atomic propositions by actual analysis. Of this I am now very doubtful, and I cannot therefore be sure that they may not be discovered to be all of one or other of a series of forms which can be expressed by $\mathrm{R}_{1}(\mathrm{x}), \mathrm{R}_{2}(\mathrm{x}, \mathrm{y}), \mathrm{R}_{3}(\mathrm{x}, \mathrm{y}, \mathrm{z})$, etc., in which case we could, as Mr Russell has suggested, define individuals as terms which can occur in propositions of any of these forms, universals as terms which can only occur in one form. This I admit may be found to be the case, but as no one can as yet be certain what sort of atomic propositions there are, it cannot be positively asserted; and there are no strong presumptions in its favour, for I think that the argument of my article establishes that nothing of the sort can be known a priori.

And this is a matter of some importance, for philosophers such as Mr Russell have thought that, although they did not know into what ultimate terms propositions are analysable, these terms must nevertheless be divisible into universals and particulars, 
categories which are used in philosophical investigations as if it were certain a priori that they would be applicable. (Ramsey $(1990,31)$ )

6.

I want to close this paper first by tying up some loose ends presented by the passages deployed by the various parties in the debate of section one, and then finally by making a connection between the Tractarian insistence that logical form is available only a posteriori and a central aspect of Wittgenstein's later philosophy.

The key passages adduced in favour of attributing Platonism to Wittgenstein were Wittgenstein's declaration on June 151916 that 'Relations and properties, etc. are objects too' (Wittgenstein $(1979,61)$ ) and Desmond Lee's record of Wittgenstein's explanation in 1930 or 1931 that Tractarian “"[o]bjects” also include relations' (Wittgenstein $(1980,120)$ ). A first thing to note here is that it is not immediately obvious what significance to attach to these two passages. The first was written at a time of experimentation and rapid development; the second is something of whose accuracy as a record of something Wittgenstein actually said we cannot be wholly confident. Such doubts voiced, we may however readily find these passages to make assertions representative of the Tractarian position. The reading would be that Wittgenstein is not with these remarks endorsing the Russellian categories and saying that he uses his term 'object' to denote an entity from any of these categories. Roughly put, his point is rather that something is not to be excluded from Tractarian objecthood simply because Russell would have called it a universal. Slightly more carefully made the point would be as follows. Take a word you might at first glance think of as indicating a universal (a property or relation). That that is a first way of thinking about it does not tend to show that it does not in fact refer. It might well be a genuine name: there may well be such an entity as that which you might naively take the word to refer to. (Of course, we will have to see how the proposition of which the word is a part is analysed in order to substantiate any such claim, and further, if it is substantiated, to clarify the logical nature of entity referred to). In this highly attenuated sense, Wittgenstein does indeed come down in favour of Platonism.

On the other side of the debate, Griffin and Ricketts both adduce remarks from Wittgenstein's 1913 writings - remarks identical or very similar to those noted in section one above - in support of their thesis that Tractarian objects are particulars. My response to such appeals is not to deny that these 1913 passages show Wittgenstein to have held something like the thesis that what are referred to are particulars, but simply to suggest that this idea was given up well before the drafting of the Tractatus. The Notes on Logic does not represent Wittgenstein's mature position. (On 19 June 1915 Wittgenstein wrote: There doesn't after all seem to be any setting up of a kind of logical inventory as I formerly imagined it (Wittgenstein $(1979,66))$.)

That Wittgenstein's ideas changed significantly between 1913 and 1918 should, I think, be taken into account also when considering the other key passage at issue in the debate of section one, namely the discussion in Tractatus 3.1432 of the propositional sign 'aRb'. Tractatus 3.1432 sits in a passage running from section 3.14 through to 3.144 whose concern is to press - repeatedly - that 'a propositional sign is a fact' (Wittgenstein $(1961,3.14)$ ) and so is neither a name nor a mere assemblage of names. The purpose of section 3.1432 is to provide an illustration of this point. The example it discusses, however, looks very much as if it is drawn from a Russellian concept script, and to the extent that it does it might appear to indicate a commitment of some kind to Russell's logical categories. (This appearance holds, of course, whether you give the passage the reading recommended by the Platonist or the one recommended by the nominalist.) Section 3.1432 is, we should however note, drawn directly from the Notes on Logic, and thus was penned at a time when Wittgenstein did indeed subscribe to something like a Russellian script. By the time of the Tractatus this subscription has been cancelled and the 'aRb' example is, I would therefore suggest, an anachronism. Wittgenstein's continued use of it is, we should note, nonetheless not mysterious. Outdated as it may be, the example has not been replaced. There is no alternative Tractarian concept script from which to pick a propositional sign to use instead of 'aRb'. Wittgenstein's 1913 example of a propositional sign is as good as any available to him in 1918 with which to press home his thesis that propositional signs are facts.

Nothing I have said in this paper which goes very far by itself towards explaining why Wittgenstein held logical form to be discernable only in the performance of analysis. This is a further question whose answering would be no small task. Very quickly, however, I want finally to suggest that Wittgenstein's Tractarian attitude towards the uncovering of logical form may be seen as an early version of his insistence that in order more clearly to see the workings of language 'we must focus on 
the details of what goes on; must look at them from close to' (Wittgenstein $(1953, \S 51)$ ). To lay down the atomic forms a priori is precisely not to learn by looking at the details from close to. It is to insist in advance that things must be a certain way and not to investigate how they in fact are.

\footnotetext{
${ }^{1}$ Wittgenstein 1979 p 106.

${ }^{2}$ Much of the material used in this section for understanding the Tractarian doctrine that elementary forms are available only through analysis comes from the year 1929. By this time Wittgenstein had given up on the idea that elementary propositions are logically independent, and to that extent (at least) his idea of truth functional analysis was not unmodified. It is unclear, however, that this development challenges any of the lessons I draw. It is unfortunate that Wittgenstein chose not to discuss the project of analysis in any detail in the Tractatus itself.

${ }^{3}$ See Wittgenstein 1995 pp.186-187.
}

\section{References}

Griffin, N.: 1964, Wittgenstein's Logical Atomism, Clarendon Press, Oxford.

Hacker, P.M.S.: 1989, Insight and Illusion, Thoemmes, Bristol.

Hintikka, M B. and Hintikka J.: 1986, Investigating Wittgenstein, Blackwell, Oxford.

Ishiguro, H.: 2001, 'The So-called Picture Theory: Language and the World in Tractatus LogicoPhilosophicus', in Glock (ed.), Wittgenstein: A Critical Reader, Blackwell, Oxford, pp. 26-46.

Kenny, A: 1984, The Legacy of Wittgenstein, Blackwell, Oxford.

Pears, D: 1987, The False Prison (volume 1), Clarendon Press, Oxford.

Ramsey, F. P.: 1990, Philosophical Papers, Mellor (ed.), CUP, Cambridge.

Ricketts, T.: 1996, 'Pictures, logic, and the limits of sense in Wittgenstein's Tractatus', in Sluga and Stern (eds.), The Cambridge Companion to Wittgenstein, CUP, Cambridge, pp. 59-99.

Russell, B.: 1984, Theory of Knowledge, the 1913 manuscript, The Collected Papers of Bertrand Russell vol. 7, E.R. Eames (ed.), Allen and Unwin, London.

Stenius, E.: 1960, Wittgenstein's “Tractatus": a critical exposition of its main lines of thought, Blackwell, Oxford.

Wittgenstein, L.: 1953, Philosophical Investigations, Anscombe (tr.), Anscombe and Rhees (eds.), Blackwell, Oxford.

Wittgenstein, L.: 1961, Tractatus Logico-Philosophicus, Pears and McGuinness (tr.), Routledge, London.

Wittgenstein, L.: 1979, Notebooks 1914-1916, Anscombe (tr.), von Wright and Anscombe (eds.), Blackwell, Oxford.

Wittgenstein, L.: 1979a, Ludwig Wittgenstein and the Vienna Circle, Schulte and McGuinness (tr.), McGuinness (ed.), Blackwell, Oxford.

Wittgenstein, L.: 1980, Wittgenstein's Lectures, Cambridge 1930-1932, Lee (ed.), Blackwell, Oxford. 
Wittgenstein, L.: 1993, Philosophical Occasions, Klagge and Nordmann (eds.), Hackett, Indianapolis.

Wittgenstein, L.: 1995, Cambridge Letters, McGuinness and von Wright (eds.), Blackwell, Oxford. 